\title{
e
}

\section{ACHIEVING CARE AND SOCIAL Justice for PeOPle WITH DEMENTIA}

\section{Marian Barnes and Tula Brannelly}

Key words: carers; ethic of care; human rights; older people

This article draws on two studies that have used an ethic of care analysis to explore lay, nursing and social work care for people with dementia. It discusses the political as well as the practice application of ethic of care principles and highlights the necessity to understand both what people do and the meanings with which such practices are imbued in order to identify 'good care' and the relationship between this and social justice. Examples of care for people with dementia are discussed by reference to core principles of an ethic of care: attentiveness, responsibility, competence, responsiveness and trust. These illustrate the potential for the development of a shared language within which different disciplines, lay carers and people with dementia can communicate about how needs could best be met in complex and difficult circumstances.

\section{Introduction}

The re-emergence of a concern with the value base of social and health care practices and policies can be considered as a reaction to the dominance of managerialism within human service organizations and to case management as the pre-eminent model of practice. ${ }^{1-3}$ Another source of opposition to such practices has been the work on antioppressive practice ${ }^{4}$ as a more overtly political response that seeks to make an alliance with the claims coming from service user organizations.

A feminist ethic of care has been used as a framework within which to analyse social policies. ${ }^{5-8}$ Particular attention has been given to the analysis of child and family policy from this perspective. ${ }^{9-11}$ Others have been concerned with issues of ethics and values in social work practice ${ }^{12-14}$ and other health and social care practices. ${ }^{15-18}$ In this journal considerable attention has been given to the everyday ethics of caregiving, especially to marginalized groups such as older people and those residing in nursing homes. ${ }^{19,20}$

'Care' is a contested concept from the perspective of service user movements. However, from within the UK disability movement, Morris ${ }^{21}$ and Shakespeare ${ }^{22}$ have suggested ways in which the perspective offered by the feminist ethic of care can enable a dialogue with the rights discourse of this movement. Kittay ${ }^{23}$ addresses

Address for correspondence: Professor Marian Barnes, School of Applied Social Science, Mayfield House, University of Brighton, Falmer, Brighton, Sussex BN1 9PH, UK. E-mail: marian.barnes@brighton.ac.uk 
ethical issues within the domains of both lay and paid care, with a particular focus on developing principles of justice capable of accommodating the 'dependency' of severely disabled people and the 'dependency work' of those who care for them. In this article our focus is on the everyday practice of caregiving involving people with dementia and the significance of an ethic of care to understanding how this could contribute to social justice in this context. We understand social justice as being based in a belief that all individuals are of equal worth and are thus entitled to be able to meet their basic human needs, experience equality of opportunity and be protected from unjustifiable inequalities. ${ }^{24}$ We use insights from two research projects ${ }^{25,26}$ to demonstrate that an ethic of care has equal relevance to the practices of paid workers in a variety of settings and to the care and support offered by family or other lay caregivers, and also emphasize the perspective of the care receiver as an integral part of ethical practice. The first was an observation and interview study of how community psychiatric nurses and social workers facilitated citizenship for people with dementia. ${ }^{25}$ The second used narrative interviews with family carers to understand what caregiving means to them, in particular how notions of both care and justice might be intertwined in their accounts of caregiving. ${ }^{26}$ Both these studies were undertaken in England, but the ethic of care analysis has also been applied in the Netherlands, the USA and South Africa, and one of our arguments is that this perspective provides a language in which fundamental issues about the practice of care can be discussed regardless of professional, organizational and cultural contexts.

\section{An ethic of care}

Since Gilligan's $\mathrm{s}^{27}$ identification of gender differences in moral reasoning, an ethic of care has been developed and applied in a number of ways. ${ }^{28-30}$ Our approach draws from the way in which political philosophers Tronto ${ }^{31}$ and Sevenhuijsen ${ }^{32}$ have developed this perspective. Both these authors promote care as a political value as well as one that concerns interdependencies between people in their private lives. Sevenhuijsen in particular has argued that social policies should be based in an ethic of care ${ }^{33}$ and has developed an analysis to interrogate social policies from this perspective. ${ }^{34}$ The perspective challenges the notion of care as a natural expression of women's capabilities, as well as the idea that it is only some people who need care. Tronto writes:

On the most general level we suggest that caring can be viewed as a species activity that includes everything we do to maintain, continue and repair our 'world' so that we can live in it as well as possible. That world includes our bodies, ourselves and our environment, all of which we seek to interweave in a complex, life-sustaining web (p. 103). ${ }^{31}$

Thus care includes both self-care and care for others: it does not oppose dependence and independence but recognizes that we are all givers and receivers of care at different times; it is not linked to gender or 'women's work'; it acknowledges bodily, spiritual and material aspects, the perspectives of caregivers and care receivers, the existence of power and conflict within care, and the moral dimension of care.

Care as a practice recognizes messy moral dilemmas that can be resolved only through moral deliberation or 'muddling through' in particular contexts. A caring orientation is acquired through engaging in caring practices and reflecting and debating 
the values necessary for care; hence we have to understand what people actually do and the meaning with which such actions are imbued. Caring practices are constructed within relationships through processes of narrative that generate understandings of how the moral principles of care need to be applied within these particular contexts. ${ }^{26,35}$

Tronto outlined four moral principles of care:

- Attentiveness: to recognize and be attentive to others;

- Responsibility: to take responsibility for action;

- Competence: caring work should be competently performed;

- Responsiveness: the position of care receivers should be considered from their perspective.

Sevenhuijsen added a fifth principle, 'trust'. She argues that trust is always interwoven with power and responsibility in conditions of vulnerability and that power should be used in a positive and creative manner. We consider the interaction between trust and other principles below.

These moral principles can act as a guide to different forms of practice. They do not prescribe a precise form of practice nor do they define procedural guidelines to be followed. Ethic of care principles draw attention to the need to focus care on the care receiver, the caregiver and the relationship between them. Good care requires a continual negotiation between those providing and those receiving care. Such an approach can accommodate the range of care providers involved, particularly in complex circumstances, because it is based in the social relationships of care and values reciprocity in the process of giving and receiving care.

Developing policies and practices based on ethic of care principles has the potential to enable an effective dialogue between paid and lay carers, and to include the perspective of the care receivers. It provides a language within which those responsible for planning and delivering care services can talk about the help they need with those who receive care and with family members. Stone ${ }^{36}$ identified the way in which justice and fairness in caregiving are defined differently by caregivers and formal organizations, but her analysis also revealed the similarities between ideas of what good care consists of, regardless of context. Paid care is compared with care by families in order to define 'good care', and 'caring' is distinguished from 'doing a job'. From an analysis of studies carried out with a wide range of care providers Stone identified the following characteristics of 'caring':

- Listening and talking, rather than carrying out tasks without words;

- Emotional attachment rather than detachment;

- Capacity to reconcile the moral imperatives of treating all service users equally, while responding to the uniqueness of each person;

- Spending time building up trust, rather than prioritizing sticking to the schedule;

- Being able to go beyond the boundaries of a professional or employment relationship;

- Working through relationships rather than rules: seeing company and friendship as a priority.

These characteristics can be related to the ethic of care principles elaborated by Tronto: attentiveness, responsibility, competence and responsiveness. 
Attentiveness requires listening to understand the circumstances of those seeking help. Appropriate responses to the words of others demonstrate that attention is being given to what is and what is not said. Enabling others to talk and thus helping the helpers to learn about their needs and circumstances is a key task. Attentiveness is a way of recognizing the uniqueness of the situations of each older person and family carer and thus helping to reconcile equal treatment with uniqueness. It is not necessary to love or even like individual people in order to be attentive and to treat them with respect and dignity. An ethic of care recognizes the reality of inequality, individuality and diversity.

Care involves accepting responsibility to act. Assuming responsibility to act on the basis of attentiveness to the particularities of the needs of service users and carers requires the capacity to 'judge with care' in relation to particular social and cultural circumstances. Responsibility is not shown in applying a set of formal rules in a detached manner, but in being prepared to spend time in building trust and understanding.

This is also relevant to an application of competence in practice. Older people and carers will not trust paid workers who perform incompetently, and arguing that workers are following a code of practice or simply applying organizational policies will be an inadequate defence in situations where it is not possible to identify some positive effect of intervention.

In defining responsiveness as the fourth moral principle Tronto highlights the significance of acknowledging that one of those involved in a caring relationship is likely to be more vulnerable than another. Tronto identifies the particular 'moral moment' related to this as the responsiveness of the care receiver to care in conditions of vulnerability and inequality. It implies that the nature of the relationship between care providers and care receivers is central to the capacity to provide good care because care is an interactive process. By including the response of the care receiver in this way Tronto emphasizes that the vulnerability of the care receiver is not an excuse for paternalism (or maternalism), and that we should not interpret the care receiver's response as if it were our own.

At an individual level the argument is that practices based in these principles are necessary to ensure that people who need additional help to access their human rights can do so. If such practices are to be feasible they need to be located within policies and service systems that support them.

\section{Care in practice}

Here we discuss these principles in the context of examples of caring for people with dementia, drawing from observations and interviews from the two research studies. This material is discussed in more detail in other publications by the authors. ${ }^{25,26}$ These examples demonstrate moral dilemmas faced in everyday caregiving, both lay and paid, and illustrate the importance of a relational approach to the achievement of social justice, rather than one based in individual rights.

\section{Attentiveness}

When care receivers find it hard to communicate, understanding their circumstances and wishes can be a difficult process. Knowledge of the persons, their histories and 
their preferences can help understanding. However, the two studies also demonstrate that an absence of attentiveness to the situations of caregivers can mean that their needs for care go unmet and their capacity to care is compromised.

Daniel's wife Margaret had been admitted to a nursing home after a stroke made it impossible for him to continue looking after her at home. ${ }^{26}$ He saw that the staff in the nursing home did not have time to sit and talk with Margaret and that she was often thirsty because staff had not helped her to drink. Thus Daniel advocated Margaret's needs, or met them himself. Daniel also discussed how uncared for he felt. Although his life revolved around ensuring that Margaret was cared for, he identified an absence of attentiveness to his needs because as 'caregiver' he was not recognized as also needing to receive care:

I go home; I don't think anybody knows I'm alive actually ... nobody comes to see me. I'm there, looking after myself, cooking my meals and doing everything that has to be done (p. 91). ${ }^{26}$

Emily's husband Edward had developed multi-infarct dementia and she had looked after him for nearly 10 years before she became ill and Edward was admitted to a nursing home, where he died. ${ }^{26}$ Her admission to hospital resulted from a lack of attentiveness to her needs and this in turn meant that Edward was unable to die at home, which both he and Emily had wanted.

Ellen was a community psychiatric nurse who also cared for her father who had dementia. ${ }^{25}$ She identified the emotional difficulties of caring for a person with dementia as most problematic. She used her own experiences to identify the importance of attentiveness to what might be unspoken pressures in caregiving.

One of the things that I did in the middle of the night with my dad was shout at him, and I was distraught afterwards. I couldn't believe that I did it. You know, I had had no sleep, I was tired, it was pure frustration, and that is exactly what we leave carers to face. Then we leave them to deal with what they have done as well [unpublished narrative].

Attentiveness has an important emotional dimension. Alan had cared for his mother, Catherine, when he was young and she had been a heavy drinker. ${ }^{26}$ In midlife he cared for her in his own home when she developed dementia. He used his experience and contacts from working as a nurse, social worker and social work manager to create a team of helpers that he co-ordinated. He understood his mother's need for care as comprising both physical and mental comfort. His experience of Catherine was as a poor parent, but despite this he was attentive not only to her desire not to go into a home but also to her need to reconstruct her earlier life:

She would say it again and again, 'I was a good mother, I worked hard and did my best for all of you.' ... She had a very strong ability to paint herself in a good light. That was one of her survival techniques and I didn't want to take that away from her in any shape or form (p. 68). ${ }^{26}$

Normative assumptions sometimes get in the way of the active listening and talking necessary to find an appropriate way through difficulties. A common assumption is that caring for persons with dementia until their death is an unachievable aim 
owing to the heavy burden it places on the carers. Practitioners are also highly attuned to the potential for abuse within caring relationships and may assume that the 'best' option is a move into residential care. Darkus was an African Caribbean man who lived with his daughter, a single mother with three children. ${ }^{25}$ The social worker recommended that he move into a residential care facility due to the presumed 'risk' he presented to the young children. Darkus' daughter felt that neither she nor her father were ready for this, but there was no discussion that might have enabled a more appropriate response.

These examples suggest that practitioners can find it hard to engage in the type of dialogue with both caregivers and care receivers that would establish what would actually help in particular situations. In the absence of such attentiveness, the 'care' that is provided is often not experienced as 'good care' and both carers and people with dementia can feel unjustly treated as a result.

\section{Responsibility}

A relational ontology ${ }^{33}$ recognizes that individuals can exist only because they are members of networks of care and responsibility, and this has implications for the way in which we think about obligations to others. This reflects the way in which lay carers spoke about their lives and experiences. ${ }^{26}$ They accepted responsibility for care in the context of the relationships in which they were involved and tried to find ways of balancing responsibilities for care receivers with responsibilities to themselves. For spouse carers a general responsibility is embedded in the marriage relationship and is usually a taken for granted, if often stressful and upsetting, response to ill health or disability. This was evident in the stories told by both Emily and Daniel. As Alan's story demonstrates, there is more choice for filial carers and the decision to care is related to the nature and quality of previous relationships, although not in an obvious manner.

Alan had promised his mother that she would not go into a nursing home. He organized care for her and took responsibility to provide personal care himself. There were considerable sacrifices associated with this role, including no social life or time to himself. None of his siblings wanted to have anything to do with her care because she had made accusations about the nature of her husband's relationship with his three daughters. Alan's brother thought that he was providing care for his mother as a result of the closeness of their relationship, but, as the following illustrates the care he gave was not dependent on positive feelings towards his mother:

He thought our closeness was a mother-son closeness, you know you love your mother, you love your son. I said no, it wasn't about that. Our closeness was that she could have someone in the family who would guide her through things, negotiate her through things ... So it looked like I was the doting son. It looked as if I couldn't do enough for her [pause], but I didn't like her, and there were times when I hated her (p. 66). ${ }^{26}$

He reflected on what he had been taught as a nurse and social worker about the 'crap about professional distance' suggesting that it is important to distinguish an emotional engagement with the process of caregiving from loving the recipient of care. This distinction is important in considering the nature and place of 'emotional attachment' when care is provided by practitioners to anyone referred to them. 
Practitioners negotiate potentially competing professional and legislative responsibilities. This can be particularly difficult in cases where they have to act in accordance with legal frameworks, such as detention in a nursing home under the doctrine of best interests, or when compulsory detention in a psychiatric hospital is considered. Practitioners could distance themselves from the person when difficult situations arose. John was a social worker who spoke of his work with Colette. ${ }^{25} \mathrm{He}$ distanced any personal involvement that he had with Colette when he arranged residential care for her, although he described the placement as a 'sadness', as he knew she did not want this. Coping with the distressing impact of the placement and knowing the outcome could not be avoided in this situation, John removed his personal self from the responsibility of causing distress to Colette:

I think had this been my first case like this it would affect me more, but for me, you just have to learn to decide which battles you are going to fight, and it is sad to say that Colette is one of a lot of people that I have sent through that process, and I would love to see it improve. I try my best not to lose any sleep over Colette because there are 27 other people [on the case load], you know, so it isn't easy (p. 204). ${ }^{25}$

\section{Competence and trust}

Good care cannot be determined solely by reference to universal principles, but requires an understanding of care practices in specific situations. Family carer interviews revealed how important the particular knowledge they had of the person they cared for was in ensuring both appropriate care and that they could continue to take part in activities that gave their lives meaning. ${ }^{26}$ This is an important part of the principle of 'competence', which emphasizes the impact or outcome of care. Emily fought to obtain sufficient care for Edward, not only to enable him to attend concerts that he loved but also so she could attend the University of the Third Age classes that were important to her. There are ways in which practitioners can also access and use knowledge of the individual to ensure a response that relates to the uniqueness of that individual. The following illustration comes from another study. Here Okely talks of one response to her mother Bridget who contracted new-variant CJD (Creuzfeldt-Jakob disease):

The visiting social worker showed brilliant initiative. At first, Bridget refused to come out of her room to meet him. Finally, she appeared in her dressing gown. She continued to remonstrate. I slipped in somewhere that my mother had once been a social worker. My mother recalled her overall responsibility for the elderly in an entire London Borough in the 1950s. The social worker then asked if, in her past experience, she would have thought it right to check up on someone who had just had a major operation. Bridget got the point, giggled, agreed and made friends (p. 40). ${ }^{37}$

A narrative approach can help practitioners to develop understanding of those they work with to enable them to provide the 'customized' responses capable of facilitating equal but not standard care. ${ }^{28}$ Practitioners who were able to spend time with the persons with dementia, and who had developed relationships with them and their family over time, had a greater understanding of what care they would accept. Community psychiatric nurses were frequently able to spend more time with these patients than social workers, who were often case managers or called in only at times 
of crisis. In some cases nurses were involved with people with dementia and their carers for many years. Some practitioners were skilled at establishing relationships quickly. Although persons with dementia may not know practitioners' names or job, they would develop a 'feel' for them and know whether they were to be trusted. When practitioners were able to find out more about persons with dementia and their family, this led to a greater understanding of reactions to difficult situations, as well as how to help carers to continue caring, or whether other means of providing care could be negotiated. ${ }^{25}$

Practitioners have to reconcile providing care that is acceptable to a person with dementia and their carers to ensure that all parties feel they are being properly treated. This involves practitioners knowing or finding out about a person's personal and relationship history, so that they can predict what services may be more acceptable. Lay carers have good access to this knowledge. Some of the research results brought together and discussed here disclosed that effective practitioners absorbed this and thought about it in relation to services available, but to do this they needed to gain the trust of both care givers and receivers.

The key to competence is the ability of practitioners and carers to build trust through dialogue. This requires that the person with dementia trusts that the practitioners and carers are working to achieve care that is acceptable to them. Competent care arises from negotiations between carers and care receivers to achieve care that is suitable to all within the context of a shared understanding of what is possible. This can be complicated by restricted communication.

Providing competent care relies on various practitioners, carers and agencies to understand the importance of carrying out care that is agreed with the care receiver. Most of all it is reliant on the practitioners recognizing the significance that both the person with dementia and the carers have a voice, and acting on that when designing the care plan. The research used as the basis of this article revealed that, in some cases, practitioners had worked exhaustively with people with dementia to encourage their acceptance of new services, but other professionals assessed the situation differently and changed the care without negotiation so that it became unacceptable to the person with dementia. Practitioners engaged in lengthy negotiations with colleagues, for example, to persuade general practitioners to provide medication that might enable a person with dementia to sleep at night, and therefore their carers to continue to care for them at home. Practitioners understood that respite care may be unacceptable to the person with dementia, but explained their carers' need for rest and personally introduced the service and the persons with dementia agreed to try this. In these cases the way that care was negotiated was underpinned by the trust that was established between all the people involved.

This contrasted with some examples cited by lay carers. Emily was unable to negotiate either when care was provided or the substance of what care assistants did when they came to look after her husband. She continued to have to undertake tasks, such as changing incontinence pads, that put a strain on her and she had little confidence in the competence of the help provided. Alan's experiences of defensiveness from health workers meant that he was unwilling to talk to them about his mother's history and how this affected the willingness of his siblings to provide care. Some carers were suspicious of professionals and reluctant to tell practitioners the degree of difficulty they were experiencing in case this meant them being seen as not able to cope. 


\section{Responsiveness}

Responsiveness calls attention to the need to understand how care receivers react to the situation they are in, including the way in which they respond to the care they receive. We should not assume that their response is the same as ours would be.

Lay carers become familiar with the way in which care receivers react and develop a good understanding of what is and what is not acceptable to them. But they may not always be confident about what to do about this. Alan talked about seeking to control his mother's behaviour when she became disinhibited. He described how Catherine squeezed his hand or tapped him to indicate she had understood and that he should not keep going on. Daniel was surprised by Margaret's lack of response when her bed in the nursing home was removed and replaced with a mattress on the floor:

The funny thing was that she didn't say anything about that. I thought that she'd say ...

I was surprised that she never complained and said, 'Why haven't I got a bed?' (p. 90 ${ }^{26}$

He was aware of what her response would have been when she was well, but was uncertain whether he should advocate on her behalf on the basis of this knowledge. This illustrates the importance of questioning whether the absence of a negative response necessarily means acceptance.

Other data gained from the research underpinning this article showed that practitioners often viewed carers as a resource. This could result in effective collaboration where there was an open relationship in which all those involved could be candid about how care was working for them. But there were also cases where lay carers were used by practitioners to 'monitor' the care receiver. In the worst cases, practitioners then took this information and made judgements about the ability of the carer to provide care, and whether the person with dementia should be removed from them because they were unable to provide good enough care. Practitioners were not upfront and open with carers and people with dementia about this, neither did they discuss their concerns about carers' ability to care. Instead, practitioners directed care conversations towards the need for residential care, and whether the time for admission was approaching.

There were some examples of practitioners failing to understand or to accept others' experience of care when this was negative. Ernie was involved in the study of community psychiatric nurses and social workers. ${ }^{25}$ When his family were no longer able to look after him at home he was placed in a residential home, where he was unhappy, but despite his pleas to return home the placement was confirmed. In order to provide ethical care it is necessary that, despite the disabilities experienced by people with dementia, practitioners respond to negative reactions and revise interventions as needed.

\section{Conclusion}

In her exploration of dependency relationships, Kittay ${ }^{23}$ argues that the myth of independence is damaging to the pursuit of political and social practices that embody an understanding of inequality, but which are also compatible with the demands of fairness and connection. She highlights the importance of considering the circumstances 
of those who are most dependent, and of those who care for them, in order to explore the way in which social responsibility is exercised, arguing that starting from assumptions of equality will not lead to policies and practices that will meet the requirements of 'justice for all' (p. xiii). ${ }^{23}$

Ethical principles, codes of conduct and professional guidance may be designed to ensure procedural rights are respected, but are insufficient for bringing about good care. When paid carers refer to these protocols as the basis of their practice, lay carers often perceive that the practitioners do not care and that care does not influence how they practice. However, practitioners often do build relationships and create and sustain dialogues with people with dementia and their carers. Such practices are essential to the relational ethics necessary to ensure justice in situations of vulnerability.

Solutions are less likely to be acceptable when they are sought in times of great stress, such as during a crisis. Crisis intervention often means drastic change, such as detention in a nursing home with no right to appeal, and dissatisfaction is viewed as unavoidable rather than an indication of unsuitable care. An ethic of care calls our attention to the response of people in such situations and the need to ensure that their voices are not silenced.

The different professions involved in caring for older people emphasize aspects of the dialogic and relational approaches valued in an ethic of care, such as the privileged nurse-patient relationship or the social networks of the care receivers. An ethic of care creates opportunities for professionals to talk to each other and to users and carers in a language that is not defined by a particular professional perspective, and which reflects lay meanings and concerns. These opportunities create a space for cultural understanding between practitioners and families.

Relational and dialogic care enables reflectivity and interpretation to inform future care. The challenge of providing suitable care to people with dementia and others with communicative and cognitive difficulties is dependent on working out what may and may not be acceptable. Lay carers often hold the key to this understanding as they will know why a person with dementia reacts in a certain way. Using this knowledge opens up a chance for building further trust between practitioners and carers and a greater opportunity to provide better care.

Practitioners who respond to the clues that lay carers and people with dementia provide help to sustain caregiving relationships. Practitioners demonstrate their attentiveness, and people with dementia and carers recognize that the practitioners are listening and care about their lived experiences. Relational and dialogic care is also possible with people with dementia who do not have carers. Although this highly skilled work is best undertaken by very experienced practitioners so that people with dementia are able to develop a 'feel' for them, practitioners can base assessment and decision making about care on information and understanding gathered through co-constructed serial interviews with people with dementia. ${ }^{38}$

Listening to people, reacting to their needs, meeting those needs and finding out if care is acceptable to them seem to be straightforward facets of providing care. In the messiness of practice this is more likely to be achievable when care is uncomplicated, when people with dementia and their carers accept practitioners' decisions and go along with them. Practitioners deserve to be better equipped to respond to, negotiate with and provide care where it is needed without muddling through or withdrawing emotionally and leaving people with dementia and their carers in untenable circumstances. $^{39}$ 
Our argument is that ethical practice and social justice cannot be achieved on the basis of a series of moral principles. Nor is an exclusively rights-based approach adequate to ensure justice when people occupy very different positions in terms of their needs for help. Instead, this requires the application of relational models of care ethics through narrative-based approaches to practice. Using an ethic of care as a shared value base would enable different disciplines to communicate more effectively about the ethics of decision making, creating more open dialogue between service providers, and between service providers, older people and their lay carers. This in turn can enable socially just practice that does not foster competitiveness between attention to the rights of people with dementia and their carers.

Marian Barnes, University of Brighton, Brighton, UK.

Tula Brannelly, Massey University, Wellington, New Zealand.

\section{References}

${ }^{1}$ Wodarski JS, Williams-Hayes MW. Utilising case management to maintain the elderly in the community. J Gerontol Soc Work 2002; 39(4): 19-38.

${ }^{2}$ Frankel AJ, Gelman SR. Case management: an introduction to concepts and skills. Chicago, IL: Lyceum, 1998.

${ }^{3}$ Evans C, Drennan V, Roberts J. Practice nurses and older people: a case management approach to care. J Adv Nurs 2005; 51: 343-52.

${ }^{4}$ Dominelli L. Anti-oppressive social work. Theory and practice. Basingstoke: Palgrave, 2002.

${ }^{5}$ Sevenhuijsen S. Caring in the third way: the relation between obligation, responsibility and care in Third Way discourse. Crit Soc Policy 2000; 20: 5-37.

${ }^{6}$ Sevenhuijsen S, Bozalek V, Gouws A, Minnaar-McDonald M. South African social welfare policy: an analysis using the ethic of care. Crit Soc Policy 2003; 23: 299-321.

7 Williams F. In and beyond New Labour: towards a new political ethics of care. Crit Soc Policy 2001; 21: 467-93.

${ }^{8}$ Williams F. The presence of feminism in the future of welfare. Econ Soc 2002; 31: 502-19.

${ }^{9}$ Cockburn T. Children and the feminist ethic of care. Childhood 2005; 12: 71-89.

${ }^{10}$ Kittay EF. A feminist public ethic of care meets the new communitarian family policy. Ethics 2001; 111: 523-47.

${ }^{11}$ Williams F. What matters is who works: why every child matters to New Labour. Commentary on the Department for Education and Skills Green Paper Every child matters. Crit Soc Policy 2004; 24: 406-27.

${ }^{12}$ Hugman R. Professional values and ethics in social work: reconsidering postmodernism? Br J Soc Work 2003; 33: 1025-41.

${ }^{13}$ McBeath G, Webb SA. Virtue ethics and social work: being lucky, realistic and not doing one's duty. Br J Soc Work 2002; 32: 1015-36.

${ }^{14}$ Parton N. Rethinking professional practice: the contributions of social constructionism and the feminist 'ethics of care'. Br J Soc Work 2003; 33: 1-16.

${ }^{15}$ Aveyard H, Edwards S, West S. Core topics of health care ethics. The identification of core topics for interprofessional education. J Interprof Care 2005; 19: 63-69.

${ }^{16}$ Harrison S, Smith C. Trust and moral motivation: redundant resources in health and social care? Policy Politics 2004; 32: 371-86.

${ }^{17}$ Hess JD. Gadow's relational narrative: an elaboration. Nurs Philos 2003; 4: 137-48.

${ }^{18}$ Reitz-Pustejovsky M. Is the care we provide to homeless people just? The ethic of justice informing the ethic of care. J Soc Distress Homeless 2002; 11: 233-48.

${ }^{19}$ Teeri S, Leino-Kilpi H, Välimäki M. Long-term nursing care of elderly people: identifying ethically problematic experiences among patients, relatives and nurses in Finland. Nurs Ethics 2006; 13: 116-29. 
${ }^{20}$ Kalis A, Schermer MHN, van Delden JJM. Ideals regarding a good life for nursing home residents with dementia: views of professional caregivers. Nurs Ethics 2005; 12: 30-42.

${ }^{21}$ Morris J. Impairment and disability: constructing an ethics of care that promotes human rights. Hypatia 2001; 16(4): 1-16.

${ }^{22}$ Shakespeare T. Help. Birmingham: Venture Press, 2000.

${ }^{23}$ Kittay EF. Love's labor. Essays on women, equality and dependency. New York: Routledge, 1999.

${ }^{24}$ Commission for Social Justice. Social justice. Strategies for national renewal. London: Vintage, 1994.

${ }^{25}$ Brannelly PM. Citizenship and care for people with dementia [Thesis]. Birmingham: University of Birmingham, 2004.

${ }^{26}$ Barnes M. Caring and social justice. Basingstoke: Palgrave, 2006.

${ }^{27}$ Gilligan C. In a different voice: psychological theory and women's development. Boston, MA: Harvard University Press, 1982.

${ }^{28}$ Noddings N. Caring: a feminine approach to ethics and moral education. Berkeley, CA: University of California Press, 1984.

${ }^{29}$ Held V. Feminism and moral theory. In: Kittay EF, Meyers DT eds. Women and moral theory. Totowa: Rowan and Littlefield, 1987: 111-28.

${ }^{30}$ Ruddick S. Maternal thinking: towards a politics of peace. Boston, MA: Beacon Press, 1989.

${ }^{31}$ Tronto JC. Moral boundaries: a political argument for an ethic of care. New York: Routledge, 1993.

${ }^{32}$ Sevenhuijsen S. Citizenship and the ethics of care: feminist considerations on justice, morality and politics. London: Routledge, 1998.

${ }^{33}$ Sevenhuijsen S. The place of care. The relevance of the feminist ethic of care for social policy. Feminist Theory 2003; 4: 179-97.

${ }^{34}$ Sevenhuijsen S. Trace: a method for normative policy analysis from the ethic of care. Paper prepared for the seminar Care and Public Policy; 2003 Nov 9-11; University of Bergen, Norway.

${ }^{35}$ Brechin A, Barton R, Stein J. Getting to grips with poor care. In: Stalker K ed. Reconceptualising work with carers: new direction for policy and practice. London: Jessica Kingsley, 2003: 160-76.

${ }^{36}$ Stone D. Caring by the book. In: Harrington Meyer M ed. Care work: gender, labor and the welfare state. New York: Routledge, 2000: 89-111.

${ }^{37}$ Okely J. Love, care and diagnosis. In: Kohn T, McKechnie R eds. Extending the boundaries of care: medical ethics and caring practices. Oxford: Berg, 1999: 19-48.

${ }^{38}$ Shenk D, Davis B, Peacock JR, Moore L. Narratives and self-identity in later life. Two rural American older women. J Aging Stud 2002; 16: 401-13.

${ }^{39}$ Brannelly T. Negotiating ethics in dementia care: an analysis of an ethic of care in practice. Dementia 2006; 5: 197-212. 
Reproduced with permission of the copyright owner. Further reproduction prohibited without permission. 